\title{
Map-Based Exploratory Evaluation of Non-Medical Determinants of Population Health
}

\section{Claus Rinner}

University of Toronto

John P. Taranu

University of Toronto

\section{Please Cite:}

Rinner, C., \& Taranu, J. P. (2006). Map-based exploratory evaluation of nonmedical determinants of population health. Transactions in GIS, 10(4), 633-649. doi:10.1111/j.1467-9671.2006.01016.x

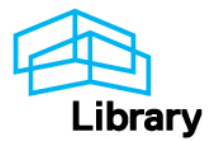




\title{
Map-Based Exploratory Evaluation of Non-Medical Determinants of Population Health
}

\author{
Claus Rinner, John P. Taranu \\ University of Toronto \\ Department of Geography \\ 100 St. George Street \\ Toronto ON M5S 3G3 \\ Canada \\ rinner(a)geog.utoronto.ca
}

Keywords: Analytic Hierarchy Process, Geographic Visualization, Health Determinants, MultiCriteria Evaluation, Spatial Decision Support Systems

\begin{abstract}
Multi-criteria evaluation (MCE) and decision-making are increasingly combined with interactive tools to assist users with visual thinking and exploring decision strategies. The interactive control of criterion combination rules and the simultaneous observation of geographic space and criterion space provide a means of investigating the sensitivity of the decision outcome to the decision-maker's preferences. The Analytic Hierarchy Process (AHP) is an MCE method that has been successfully implemented in management processes including those addressed by Geographic Information Systems. In this paper, we present a map-based, interactive AHP implementation, which provides a link between a well-understood decision support method and exploratory geographic visualization. Using a case study with public health data for the Province of Ontario, Canada, we demonstrate that exploratory map use increases the effectiveness of the AHP-based evaluation of population health.
\end{abstract}

\section{Introduction}

Geographic Information Systems (GIS) integrate thematic data using their geographic references. In decision-making problems, information about locations often has to be condensed in order to arrive at a simple preference ranking of decision alternatives. Multi-criteria evaluation (MCE) methods that achieve such data condensation include conjunctive and disjunctive decision rules, weighted averaging, the Analytic Hierarchy Process, Ideal Point Analysis, concordance methods, and Ordered Weighted Averaging. Such MCE methods have been implemented in GIS in a series of research papers in the 1990s, including Janssen and Rietveld (1990), Carver (1991), Church et al. (1992), Banai (1993), Pereira and Duckstein (1993), Jankowski (1995), and Eastman (1997). Both the GIS vector and raster data models can be used for MCE. With raster data, decision criteria are represented by multiple criterion maps and combined using map algebra. With vector data, decision criteria are stored as feature attributes and combined using algorithmic calculations in an attribute table. 
Malczewski (1999) reviews criticism on different steps in MCE processes. For example, different MCE methods tend to generate different rankings for the same decision problem. As a consequence, Heywood et al. (1995) propose to integrate a variety of MCE techniques into a single "exploratory" MCE environment. Furthermore, it is difficult to gather user preferences in terms of criterion choice, criterion standardization, and criterion weighting. However, we argue with Jankowski et al. (2001) that maps can serve as a "source of structure in multiple criteria spatial decision problems" and that interactive map manipulation addresses this criticism on MCE. In the context of location analysis, Densham and Armstrong (1995) described this approach as a process of "decision research".

Geographic visualization draws on the increasing role of data visualization for hypothesis building in the sciences and engineering. The concept has been introduced to the spatial domain by Monmonier (1989), DiBiase (1990), and MacEachren (1994). In his well-known model of map use, MacEachren distinguishes the communication function from the visualization function of maps, the latter being associated with high human-map interaction in a private setting with the aim of "revealing unknowns". Geographic visualization is typically used to explore the original properties (attributes) of geographic objects. We suggest exploring original attributes along with (interim) results during geo-processing, thus extending the scope of geographic visualization from data exploration to data analysis. The present paper proposes a method for visual exploration and evaluation of geo-referenced data in the early stages of decision making, when decision makers first try to understand the decision space.

As the population of industrialising countries ages, improving and monitoring population health has become a key function of government agencies. This has entailed the collection of huge amounts of health-related data, which can be used to evaluate population health. This research uses indicators for Ontario public health units and evaluates the overall health status as part of a hypothetical decision-making scenario. Areas with the lowest health status can be assumed to be most in need for funding to strengthen their health system and support campaign activities. Focusing on the non-medical determinants of health we found that the inherent hierarchy in this data is suitable for modeling with the Analytic Hierarchy Process (AHP) (Saaty 1980). AHP is a widely used multi-criteria decision analysis method, which is particularly effective in eliciting user preferences (Malczewski 1999).

The paper first provides an overview of the assessment of population health and describes it as a multi-criteria evaluation problem (Section 2). We then summarise the AHP method (Section 3) and describe our interactive, map-centred approach to using the AHP (Section 4). We further introduce a case study based on Ontario health indicators (Section 5) and conclude the paper with a discussion of our findings and an outlook on future research (Section 6).

\section{Assessing Population Health as a Decision Support Problem}

Governments on different levels, from national/federal to provincial to municipal, strive to provide equal or similar health conditions across their jurisdictions. For example, the research mandate of the Canadian Institute of Population and Public Health includes "analyzing and reducing health disparities" between population subgroups including those defined by geography (IPPH 2002). Public health is a complex concept that is usually seen as reflecting people's quality of life beyond the mere absence of disease. Therefore, numerous factors contribute to the overall health status of a community, including health determinants in people's living environment and behaviours. Previous studies found strong correlations between socio-economic factors (such as 
income, education, and employment) and health status (Birch et al. 2000, Irbarren et al. 2001, Kosteniuk and Dickinson 2003, Wen et al. 2003).

In the Canadian Community Health Survey (CCHS), Statistics Canada collected health indicators for Public Health Regions including non-medical determinants of health. The latter include socio-economic variables as well as health-related behaviours such as smoking and drinking. Understanding the spatial distribution of these health determinants will allow for taking spatially differentiated action to improve population health. Goel et al. (1996) note the lack of a comprehensive measure for population health across the Province of Ontario. Discussing health indicators individually, Goel and colleagues found lower health status in areas of Northern Ontario compared to central and southern Ontario. Statistics Canada (2002) explores community health through multi-variate regression analysis of health outcomes and risk factors.

There is considerable interest by public health researchers and practitioners in employing GIS to integrate, visualize, and assess population health indicators. Government publications such as the Atlas of Canada include maps of health determinants (e.g. NRCan 2004). Rushton (2003) discusses advances in geo-referencing of health information and the use of spatial analysis methods in the public health community. An exploratory approach to knowledge discovery in multi-dimensional health databases is proposed by Bédard et al. (2003).

In the case study examined in this paper, we suggest assessing population health based on multiple health determinants using a map-based exploratory evaluation method. Multi-criteria evaluation provides for a transparent combination of health factors with the potential to support more informed community health planning.

As a multi-criteria decision problem, the evaluation of health status is exposed to the same criticisms as MCE methods in general, namely the difficulty of weighting larger numbers of criteria, and weighting criteria fairly, as well as the observation that different methods will generate different evaluation results. Therefore, we argue that interactive MCE methods in combination with geographic visualization should be used to attenuate these problems. Health determinants such as those from Statistics Canada are already structured in categories and subgroups, and can easily be translated into different levels of a common hierarchy. From the existing MCE methods we chose the AHP for its suitability to work with hierarchical datasets and for its support for weighting large numbers of criteria through pairwise comparison.

\section{The Analytic Hierarchy Process}

The Analytic Hierarchy Process (Saaty 1980) is a multi-criteria decision support method that is widely used in business and economics decision making. AHP users establish a hierarchy of elements of the decision problem at hand, ranging from the overall goal to objectives to attributes (decision criteria) to decision alternatives. When the AHP is applied to spatial decision problems, it is usually simplified to stop at the attribute level (Malczewski 1999).

In the user-defined hierarchy, more general, high-level concepts are placed at the upper levels, and specific attributes (decision criteria) at the leaves. Arranging elements in this way reflects one of the fundamental processes performed by the human mind: a complex problem is divided into its major components, and those components are in turn subdivided into their subcomponents (Saaty 1980). At the lowest level in the hierarchy, leaf attributes have unique values for each decision alternative. These are aggregated upwards to higher levels in the hierarchy, consolidating in the evaluation score at the hierarchy root. Based on their numeric evaluation scores, alternatives may be objectively compared. 
At each level, attributes are weighted to reflect their differing importance. A parent attribute (objective) is composed of a number of child attributes, and the weights given to the children correspond to the relative importance (or priority) between the children in calculating the score for the parent. The weights of all the children of a parent attribute must add up to $100 \%$.

The score of a parent attribute having $n$ children is calculated as $s_{\text {parent }}=\sum_{\mathrm{i}} s_{i} * W_{i}$, with children's scores $s_{i}$ and weights $w_{i}$. This process is repeated for each parent node from the bottom (leaves) of the hierarchy to the top (root). In this way, all parent attributes get a score derived from their children. The $s_{i}$ for leaf attributes (those attributes that have no children) are the original attribute values from a data table, after being standardised (e.g. to a range between 0.0 and 1.0). Since each decision alternative has different values for the leaf attributes, the entire hierarchical calculation must be repeated for each alternative.

Two methods may be used to determine the weights $w_{i}$ for attributes in the hierarchy. The first is conceptually simple - for a parent attribute with $n$ children, the users decide on $n$ weights, at once, that sum to $100 \%$. However, defining the relative importance between even a few criteria is more difficult than comparing only two items at once. To this end, Saaty (1980) has introduced a second method of determining weights, called pairwise comparison. The $n$ child attributes are compared with each other, two at a time, and the priority of attribute $i$ compared to attribute $j$ (i.e. the ratio of $w_{i}$ to $w_{j}$ ) is stored as value $a_{i j}$ in an array called the pairwise comparison matrix. With respect to the scale for the pairwise comparisons, Saaty (1980) argues that the human mind can only distinguish differences between two objects on a coarse scale, and suggests relative priority ratings from 1 ("equally important") to 9 ("extremely more important") and their reciprocals. Once the matrix is filled with priority values, the importance weights $w_{1}$ to $w_{n}$ for all child attributes are calculated by "averaging over the normalized columns" (Saaty 1980).

Pairwise comparison can lead to inconsistent decisions. For example, when comparing three attributes A1, A2, and A3, the decision-maker may set the pairwise comparisons to $a_{12}=4$, $a_{23}=2$, and $a_{31}=2$. Thus, A1 is more important than A2, A2 is more important than A3, and A3 is more important than $\mathrm{A} 1$, which is an inconsistent judgement. However, dealing with the inherent inconsistency in decision problems is a distinctive feature of AHP in contrast to many other evaluation methods. The degree of inconsistent judgement in a pairwise comparison matrix can be measured using the consistency index (C.I.) developed by Saaty (1980). The C.I. measure is then compared to the experimentally derived random index (R.I.), an average consistency index for randomly generated matrices. The ratio of C.I. / R.I. is called the consistency ratio (C.R.), and rates the inconsistency for a specific priority judgement. A C.R. value of less than 0.10 is considered acceptable, while higher values are considered too inconsistent.

\section{An Interactive Map-Based Implementation of the AHP}

The Analytic Hierarchy Process has already been implemented in a GIS context (Malczewski 1999, Zhu and Dale 2001, Eastman 2003). For the purpose of demonstrating the use of AHP in combination with interactive mapping to evaluate health indicators, a variant of AHP was implemented in CommonGIS. CommonGIS is a research tool developed within a European Union research project on "Common Access to Geographically Referenced Data" (Voss et al. 2000, CommonGIS 2005). The tool is characterised by its highly interactive mapping capabilities and dynamically linked maps and graphs. These functions support spatial data exploration rather than cartographic design and are not available in commercial GIS packages. Our AHP implementation contains all of the major components of AHP including hierarchy building and pairwise comparison and benefits from CommonGIS' interactivity to enable the exploration of decision strategies. The user can edit the AHP hierarchy and criterion weighting on the fly, and 
all changes are displayed instantly on a corresponding map representing the geographic dimension of the decision problem and the current decision outcome.

The AHP method is started in CommonGIS when the user clicks the corresponding menu option, selects a table with the relevant data, chooses the AHP method from the list of available decision support methods, and finally chooses attributes to be used as decision criteria. When this last dialog is confirmed, a default map appears immediately showing the evaluation results based on the default settings of the AHP method. This responds to Shneiderman's (2004) request for "immediate and continuous feedback" of visualization tools. Shneiderman also emphasized the mantra of information visualization: to provide "overview, zoom and filter" functionality immediately while details should be offered on-demand. These principles are addressed by the design of decision support methods in CommonGIS including the AHP method, where map navigation functions simultaneously accompany interactive analysis tools.

After the initial selections, the user is presented with the AHP method's main dialog. This consists of three tabs, comprising the three steps involved in the AHP: building the hierarchy; weighting criteria using either simple sliders or a pairwise comparison matrix; and standardising attribute values to a comparable scale. There is no required order to the steps. Even so, it makes sense to build the hierarchy first before adjusting the weights, as changing the hierarchy will upset the delicate balance between weights. Attribute standardization is the first logical step but will not be considered further as the standardization options in CommonGIS are still very limited. Score-range transformation (Malczewski 1999) is used in the AHP method.

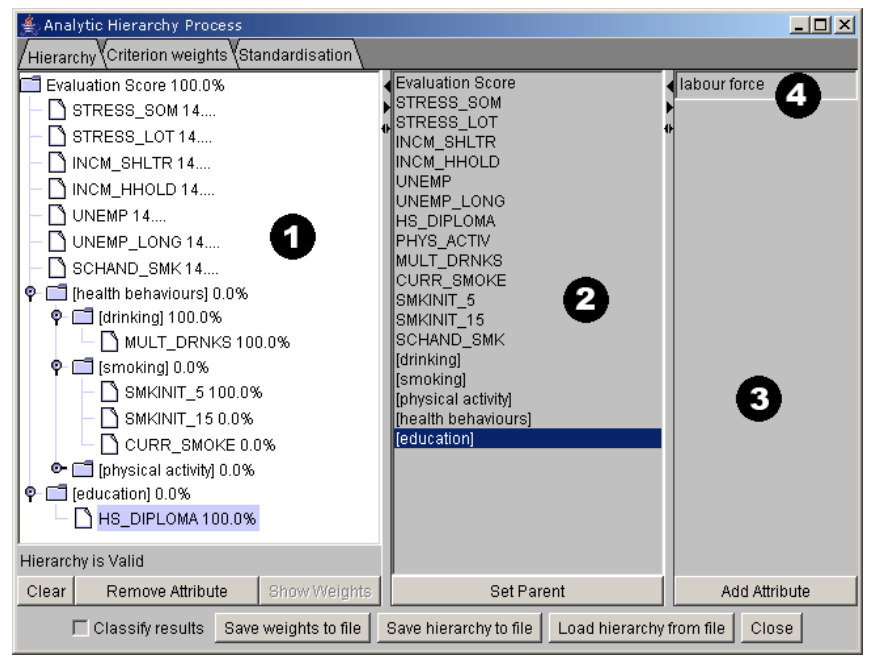

Figure 1 - Definition of criterion hierarchy in the AHP method

The "Hierarchy" tab (Figure 1) has three panels: the current AHP hierarchy is displayed on the left panel (1). In the middle is a list of all the attributes (2). On the right is a panel for creating new group attributes (3). The hierarchy has a root, the "Evaluation Score", to which are linked all the table attributes selected by the user. All table attributes must appear as leaves in the hierarchy, and the user can create non-leaf attributes for higher-level grouping. For this, the user first types the name in the textbox (4), and then clicks the "Add Attribute" button. A new group attribute is created in the hierarchy (1) with a weight of $0 \%$. To assign children to group attributes, the user selects a single child node from the hierarchy, selects a group attribute from the list in the middle (2) that will serve as the new parent, and clicks the "Set Parent" button. By assigning parents this 
way, the user may create a hierarchy with as many levels as desired. A group attribute may be removed from the hierarchy using the "Remove Attribute" button; its children will have their parent set to the root of the hierarchy. A hierarchy is considered valid if only table attributes appear as leaf nodes, and only group attributes appear as non-leaf nodes. If a hierarchy is valid the user may proceed to determining weights.

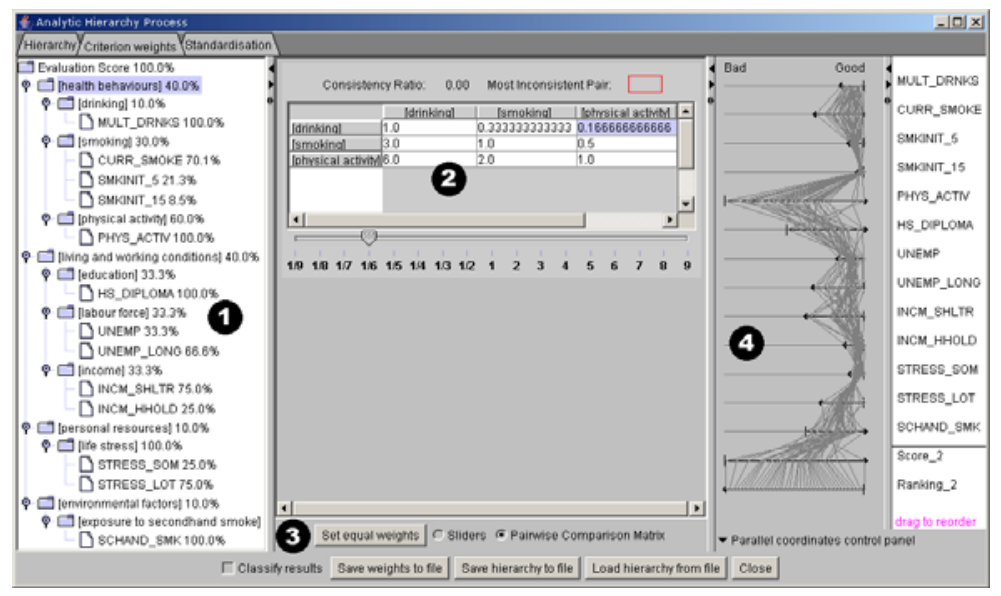

Figure 2 - Definition of criterion weights using pairwise comparison

The second tab in the AHP window is labelled "Criterion Weights" (Figure 2), where the user sets importance weights. If a parent node is selected from the hierarchy on the left (1), the centre panel (2) allows the user to enter the weights. This can be done either through a pairwise comparison matrix (see Figures 2 and 3(b)) or a simple slider panel (see Figure 3(a)). The user can switch between the two panels using a selector at the bottom (Figure 2, item 3). At the right of the window is a parallel coordinate plot (4) that shows all table attributes including the final score and ranking. This is a built-in visualisation feature in CommonGIS (Andrienko and Andrienko 2003). The vertical lines represent each decision alternative, and their position on each horizontal table attribute line depends on their score at that attribute. Benefit attributes (to be maximised) have low values on the left and high values on the right; cost attributes are reversed.

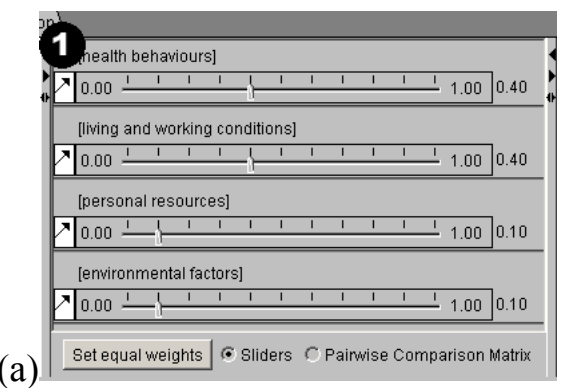

Figure 3 - Tools for criterion weighting: (a) slider panel, (b) pairwise comparison matrix

The children of the group attribute selected in the hierarchy appear in the weighting panel. Two different weight input methods are offered for the AHP method: sliders and pairwise comparison. The slider panel shown in Figure 3(a), a modified version of the built-in 
CommonGIS slider panel (Andrienko and Andrienko 2003), offers a straightforward way of changing weights. The user moves one of the sliders, representing the weight of one of the attributes, and the remaining sliders adjust to preserve a sum of weights equal to $100 \%$. An attribute can also be switched between being a cost criterion or a benefit criterion by using the arrow button on the left of each slider (1); this only applies to table attributes. Weights can be reset to equal for all attributes by pressing the "Set Equal Weights" button.

The implementation of the pairwise comparison panel (Figure 3(b)) was inspired by Divisek and Meyersiek (2001). The panel contains a matrix of $\mathrm{n} \times \mathrm{n}$ cells ( $\mathrm{n}$ is the number of child attributes in the selected group), where the cell in row $i$ and column $j$ corresponds to the relative importance of attribute $\mathrm{i}$ compared to attribute $\mathrm{j}$ (element $\mathrm{a}_{\mathrm{ij}}$ in the pairwise comparison matrix). The cells along the main diagonal are always set to 1.0, while all other cells may be modified by clicking on the cell in the table (1). A slider on the bottom (2) lets the user select any value from 1/9 through 1 to 9 for the selected cell. The corresponding cell opposite the main diagonal is updated with the reciprocal value, i.e. if cell $a_{i j}$ is changed, then cell $a_{j i}=1 / a_{i j}$. Weights of relative importance are re-calculated after every modification of the pairwise comparison matrix. Whenever the pairwise comparison panel is re-activated, the values in the pairwise comparison matrix are re-calculated from the weights currently stored in memory. Values calculated in this way may differ from the 1-9 integer (and reciprocal) scale. This design decision has been made in conflict with the original AHP definition by Saaty (1980) in order to maintain carefully considered weights. The cells in the matrix will keep their non-standard values until the user edits them by moving the slider.

The consistency ratio is shown on the top-left of the panel (3), and if it is above the threshold of 0.1 then a red border appears around the number and also around the pair of cells $\mathrm{a}_{\mathrm{ij}}$ and $\mathrm{a}_{\mathrm{ji}}$ with the single most inconsistent pairwise judgement (4). By modifying this judgment, the user can most effectively reduce the inconsistency in the matrix.

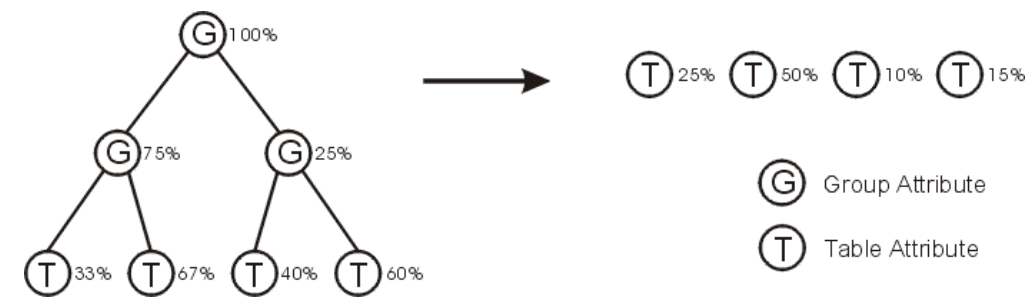

Figure 4 - Flattening of a hierarchy

AHP provides a robust way to determine attribute weights. Using the weights from an AHP session with other decision support methods would greatly add to the value of a decision support platform. Therefore, the AHP window has a button labelled "Save weights to file", which flattens the hierarchy and determines the overall weights for each table attribute. An illustration of "flattening" is shown in Figure 4. The hierarchy is not preserved because the derived group attributes do not persist in the program. The saved weights for the table attributes can then be loaded inside any method in CommonGIS that uses the weighted attribute panel, provided the same data table is used. Currently this includes weighted linear combination, ideal point analysis (Jankowski et al. 2001), and ordered weighted averaging (Rinner and Malczewski, 2002). In addition, the AHP method can also save its entire hierarchy for later re-use, preserving all the derived attributes and their weights, and load an existing saved hierarchy. This is done using the "Save Hierarchy to File" and "Load Hierarchy from File" buttons. 


\section{Case Study: Evaluation of Health Status for Public Health Units in Ontario}

Comparing regions in terms of their overall health is a complex endeavour. The AHP supports the analyst in retracing overall health status through more manageable health indicators, while at the same time producing a numeric score for overall health by which health regions can be compared and ranked. The indicators used in this case study stem from Statistics Canada (2004). This dataset has already been arranged into a hierarchical structure, with individual indicators grouped under several levels of categories. We will take a subset of the non-medical health determinants that is most relevant to our problem. These indicators are weighted in relation to each other, with the objective of assessing the overall health of each region. The decision alternatives here are Ontario Public Health Units, administrative regions that are generally arranged along county/district lines. This application is meant to provide an illustrative example of the power of a spatially enabled, exploratory AHP implementation rather than achieving a comprehensive evaluation of health status in Ontario.

There are two general approaches to dealing with a problem such as this. In a top-down approach, an expert in the field would define higher-level categories in the hierarchy first and determine the weights between them, and later gather the lowest-level attribute data. This approach reflects the conceptualization of a complex phenomenon such as population health. The bottom-up approach used here instead has the user gather available data first, then build the hierarchy and come up with the importance weights. In using the bottom-up approach, we rely on existing conceptualization of population health by experts, as provided in the health indicator framework by Statistics Canada (2005). We further argue that interactive exploratory data analysis as in the proposed method will increasingly overcome the difference between top-down and bottom-up approaches to conceptualizing criterion hierarchies.

First we will begin with a description of the attributes used and their weights within the hierarchy. All data is expressed in percentages, as the health units vary considerably in population and raw numbers would be misleading. The data attributes (such as Proportion of Current Smokers) are grouped under first-level group attributes (such as Smoking), which are then brought under second-level group attributes by their overall data type (such as Health Behaviours), following the Statistics Canada hierarchy. The second-level group attributes are finally grouped under the Evaluation Score. A description of all attributes and their grouping is shown in Table 1.

To illustrate the weighting procedure, we will use the pairwise matrix to compare the three leaf attributes in the smoking group. As the number of current smokers is considered the primary determinant of health, Proportion of Current Smokers is weighted as being moderately more important than Smoking Initiation between the Ages of 5 and 14, giving it a rating of 3. Assuming that we are more concerned with children and young teenagers smoking than with older teenagers, then Smoking Initiation between the Ages of 5 and 14 is weighted as more important than Smoking Initiation between the Ages of 15 and 19, with a rating of 4 . Finally, the proportion of current smokers is demonstrably more important than the percentage of people who started smoking as older teenagers, so Proportion of Current Smokers is given a rating of 7 over Smoking Initiation between the Ages of 15 and 19. The resulting pairwise matrix is shown in Figure $3(\mathrm{~b})$. Note the consistency ratio of 0.03 , indicating a reasonably consistent judgment. 
Table 1 - Selected non-medical determinants of health used as decision criteria (Source: Statistics Canada 2005, sample weighting by the authors as a result of pairwise comparison)

\begin{tabular}{|c|c|c|c|}
\hline & $\begin{array}{l}\text { Group } \\
\text { attributes }\end{array}$ & Attribute Name & Description \\
\hline \multirow{5}{*}{ 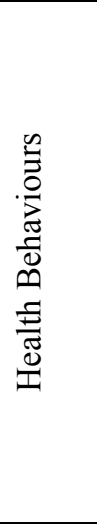 } & Drinking & MULT_DRNKS & $\begin{array}{l}\text { People reporting having } 5 \text { or more drinks, } 12 \text { or more } \\
\text { times a year. An indicator of heavy drinking habits. }\end{array}$ \\
\hline & \multirow[t]{3}{*}{ Smoking } & CURR_SMOKE & $\begin{array}{l}\text { Current smokers, both occasional and daily. Covers the } \\
\text { entire smoking population }\end{array}$ \\
\hline & & SMKINIT_5 & $\begin{array}{l}\text { Current smokers who started smoking between the ages } \\
\text { of } 5 \text { and } 14 \text {. Emphasises smoking initiation in a very } \\
\text { young, vulnerable group. }\end{array}$ \\
\hline & & SMKINIT_15 & $\begin{array}{l}\text { Current smokers who started smoking between the ages } \\
\text { of } 15 \text { and } 19 .\end{array}$ \\
\hline & $\begin{array}{l}\text { Physical } \\
\text { Activity }\end{array}$ & PHYS_ACTIV & $\begin{array}{l}\text { People reporting active or moderately active recreational } \\
\text { lifestyles. Physical activity is considered a benefit } \\
\text { criterion with high rates indicating good health. }\end{array}$ \\
\hline \multirow{5}{*}{ 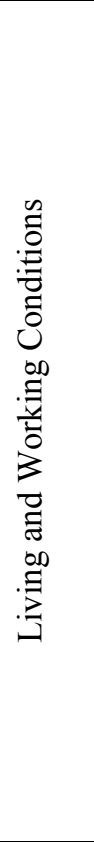 } & Education & HS_DIPLOMA & $\begin{array}{l}\text { 25-29-year-olds with a high school diploma. The } \\
\text { percentage of young adults without basic education is } \\
\text { one of the most commonly used socioeconomic } \\
\text { contributors to overall health. People without a high } \\
\text { school diploma are considered an at-risk population. }\end{array}$ \\
\hline & \multirow[t]{2}{*}{ Labour Force } & UNEMP & $\begin{array}{l}\text { Unemployment rate for people aged } 15 \text { and over. } \\
\text { Employment rates are an important indicator of } \\
\text { socioeconomic status, and indirectly of population } \\
\text { health. }\end{array}$ \\
\hline & & UNEMP_LONG & $\begin{array}{l}\text { Long-term unemployment rate. This category double- } \\
\text { counts those persons out of work for a year or more. } \\
\text { "Unemployed people tend to experience more health } \\
\text { problems. Long-term unemployment could extend ones' } \\
\text { susceptibility to poor health" (Statistics Canada, 2002). }\end{array}$ \\
\hline & \multirow[t]{2}{*}{ Income } & INCM_SHLTR & $\begin{array}{l}\text { Proportion of households spending } 30 \% \text { or more of total } \\
\text { income on shelter expenses. These households are not } \\
\text { believed to have the flexible resources to cover } \\
\text { additional expenses, and are a population at higher risk. }\end{array}$ \\
\hline & & INCM_HHLD & $\begin{array}{l}\text { Population in low-income households. An indicator of } \\
\text { socioeconomic status. }\end{array}$ \\
\hline \multirow{2}{*}{ 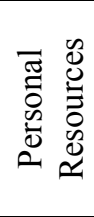 } & \multirow[t]{2}{*}{ Life Stress } & STRESS_SOM & $\begin{array}{l}\text { Population aged } 18 \text { and over who reported a moderate } \\
\text { degree of personal stress. It is assumed that stress levels } \\
\text { can contribute to health problems. }\end{array}$ \\
\hline & & STRESS_LOT & $\begin{array}{l}\text { Population aged over } 18 \text { reporting a high degree of } \\
\text { personal stress. }\end{array}$ \\
\hline 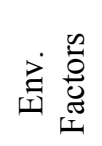 & $\begin{array}{l}\text { Second-hand } \\
\text { Smoke }\end{array}$ & SCHAND_SMK & $\begin{array}{l}\text { Population over } 12 \text { exposed to a significant amount of } \\
\text { second-hand smoke. }\end{array}$ \\
\hline
\end{tabular}




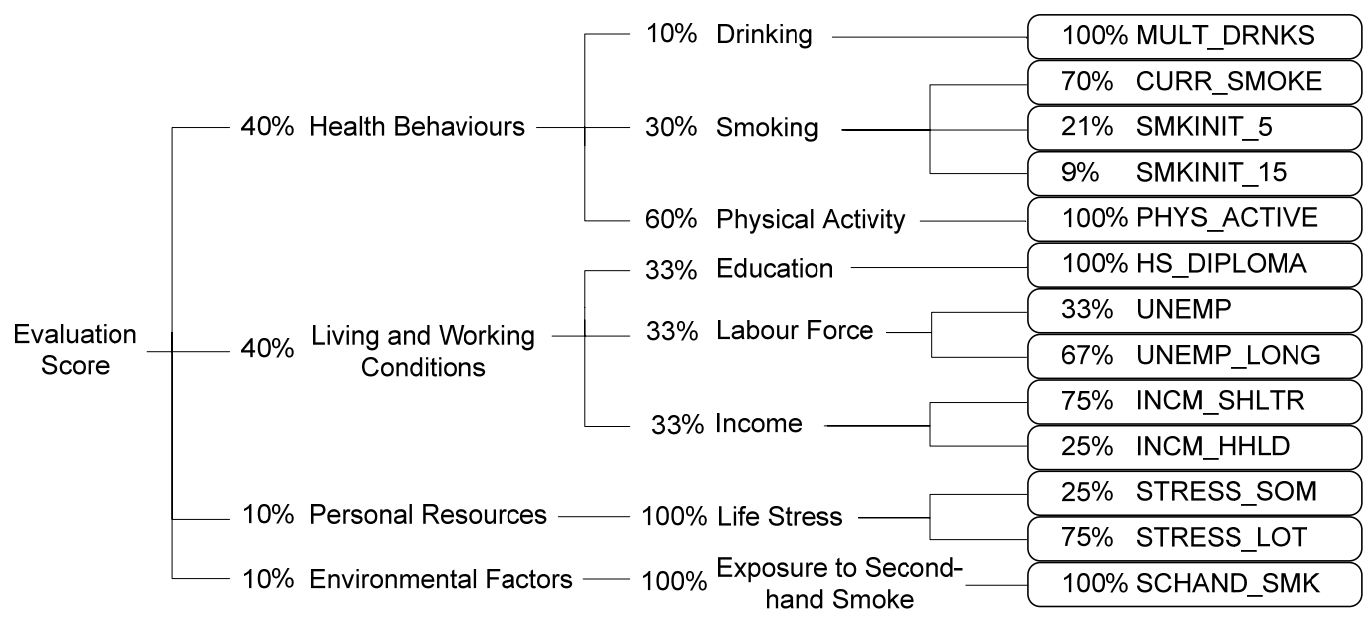

Figure 5 - Attribute hierarchy and weighting within groups

Figure 5 shows the grouping of attributes in the hierarchy and the weighting within these groups. The weighting process for Health Behaviours is described below. The Living and Working Conditions group contains Education, Labour Force and Income. All three are judged to be of the same importance, so they get equal weights. We chose to work with only one attribute per group for Personal Resources and Environmental Factors; each receives 100\% of the weight for the group.

Drinking, Smoking, and Physical Activity are grouped under Health Behaviours. As we assume Physical Activity to be a much more important determinant for population health than Drinking, we give it a priority rating of 6. It is seen as somewhat more important than Smoking, with a rating of 2. Finally, Drinking is seen as moderately less important than Smoking, so it has a 1/3 rating. The pairwise matrix is shown in the centre panel of Figure 2. The resulting weights are: Physical Activity 60\%, Smoking 30\%, and Drinking 10\%.

The four second-level group attributes (Health Behaviours, Living and Working Conditions, Personal Resources, and Environmental Factors) are grouped under the final Evaluation Score, and we will illustrate the use of sliders in determining the weights at this level (see Figure 3(a)). Living and Working Conditions contain socioeconomic indicators, while Health Behaviours contains indicators of lifestyle choices. Both of these are important, and it is difficult to weight one higher than the other. Both deserve a high priority, so both get weighted $40 \%$. Environmental Factors and Personal Resources as indirect determinants of health are assumed to be less powerful than the two first groups; both receive a weight of $10 \%$.

It is important to note that during the entire hierarchy building and weighting process, intermediate evaluation results were displayed on a map of Ontario health units. However, we discuss the results of the AHP method and the modification of user preferences only now that we have completed weighting the entire hierarchy (Figure 5). The default unclassed choropleth colouring scheme of CommonGIS is used to display ranks 1 (lightest, best overall health) to 38 (darkest, poorest overall health) on a map of Ontario as shown in Figure 6. At first glance, several interesting patterns emerge. Some of the lowest ranks appear in far Southern and Northern Ontario, excepting two public health units in the far North-West. The highest ranks occur in Central Ontario as well as the Ottawa unit in the East, which has a far better rank than the surrounding areas. Conversely, the Toronto and Peel units score lower than their surrounding regions. Why do these differences occur? 


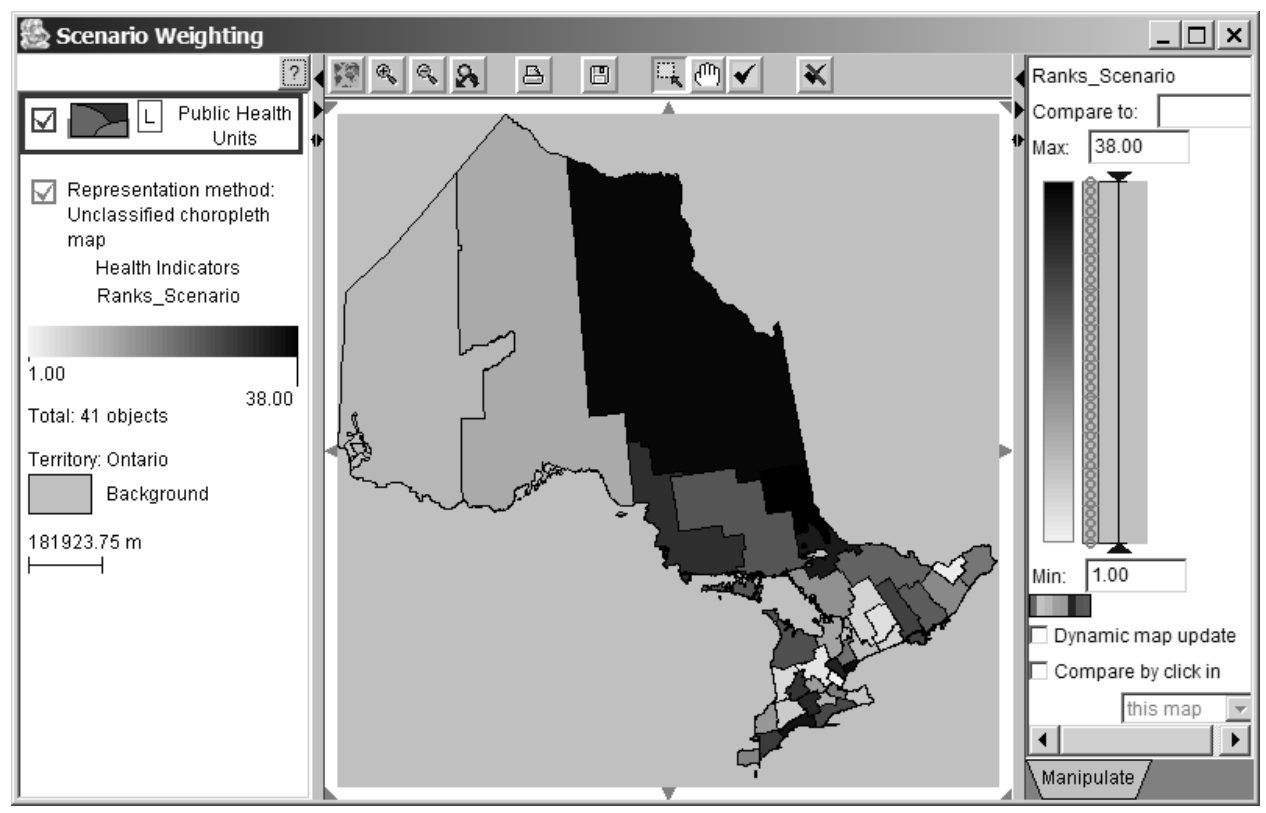
in Ontario

Figure 6 - Visualisation of resulting ranks 1 (lightest) to 38 (darkest) of public health units

(a)

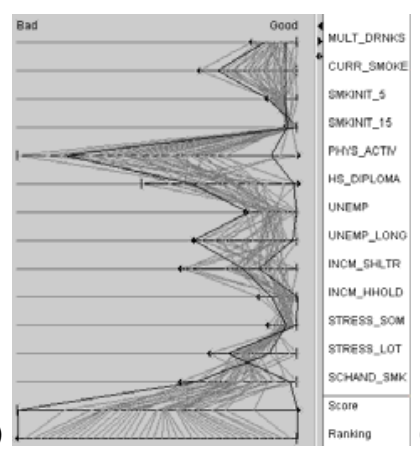

(b)

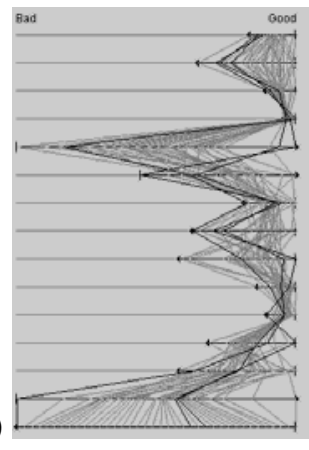

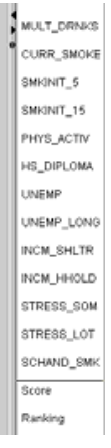

(c)

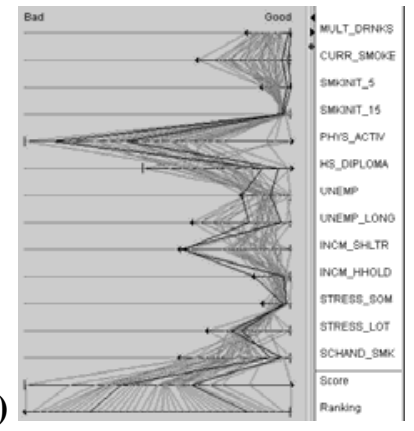

Figure 7 - Parallel coordinate plots with health units highlighted for comparison: (a) Halton and Timiskaming, (b) Timiskaming, Thunder Bay and Northwestern, and (c) Toronto and York

The parallel coordinate plot now becomes very useful. Figure 7(a) compares the highestranked area, the Halton Regional Unit of Health (located on Lake Ontario between Toronto and Hamilton), to the worst-ranked area, the Timiskaming Health Unit (in North-Eastern Ontario). Halton has high scores in nearly every attribute, while Timiskaming scores poorly in most of its attributes. Halton has very low unemployment and smoking rates, and high education and physical activity levels. Interestingly, it has high levels of people reporting high stress. Timiskaming, on the other hand, has very high unemployment, little physical activity, low education, and high smoking and drinking rates. Although its scores in most other attributes are mediocre, the high weights given to smoking, physical activity, and unemployment contribute to the health unit's very low overall rank. Indeed, most of the Northern units with poor rankings have similar scores across the attributes. By comparison the Thunder Bay and Northwestern units, located in the North-West of the province, also have similar scores across most attributes with the 
exception of very high rates of physical activity, giving the two units a favourable overall score (Figure 7(b)). Why do the neighbouring Toronto and York regions exhibit such divergent rankings? As can be seen in Figure 7(c), both regions have similarly good scores in smoking, drinking, and education rates, and similarly poor scores in high-stress rates. The biggest difference is Toronto's significantly higher rates of unemployment, and York's higher rate of physical activity.

(a)

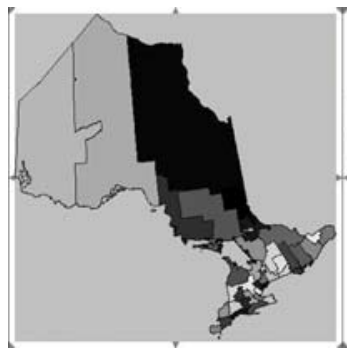

(b)

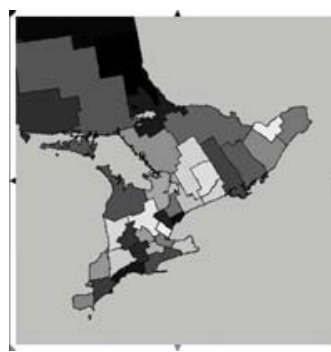

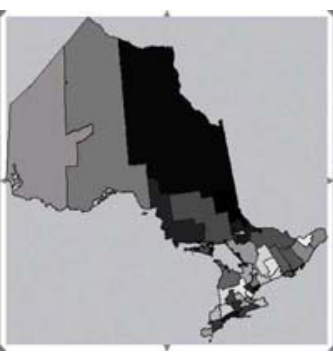

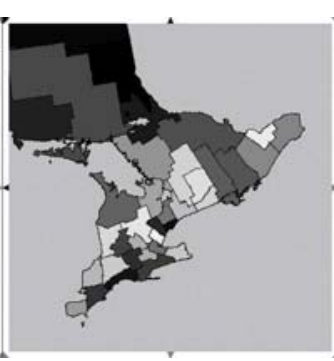

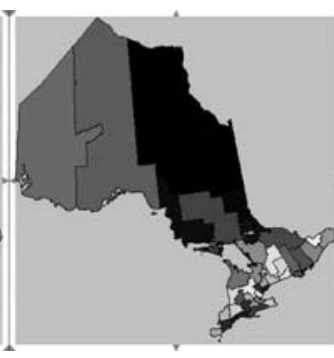
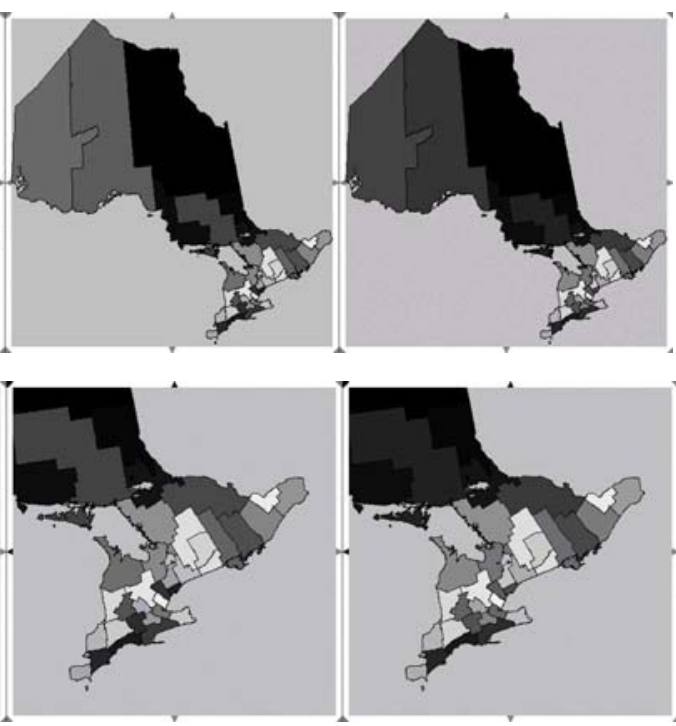

Figure 8 - Series of screen maps created when reducing the weight for Physical Activity within its group from $60 \%$ to $30 \%$ : (a) all of Ontario, (b) detail for Southern Ontario

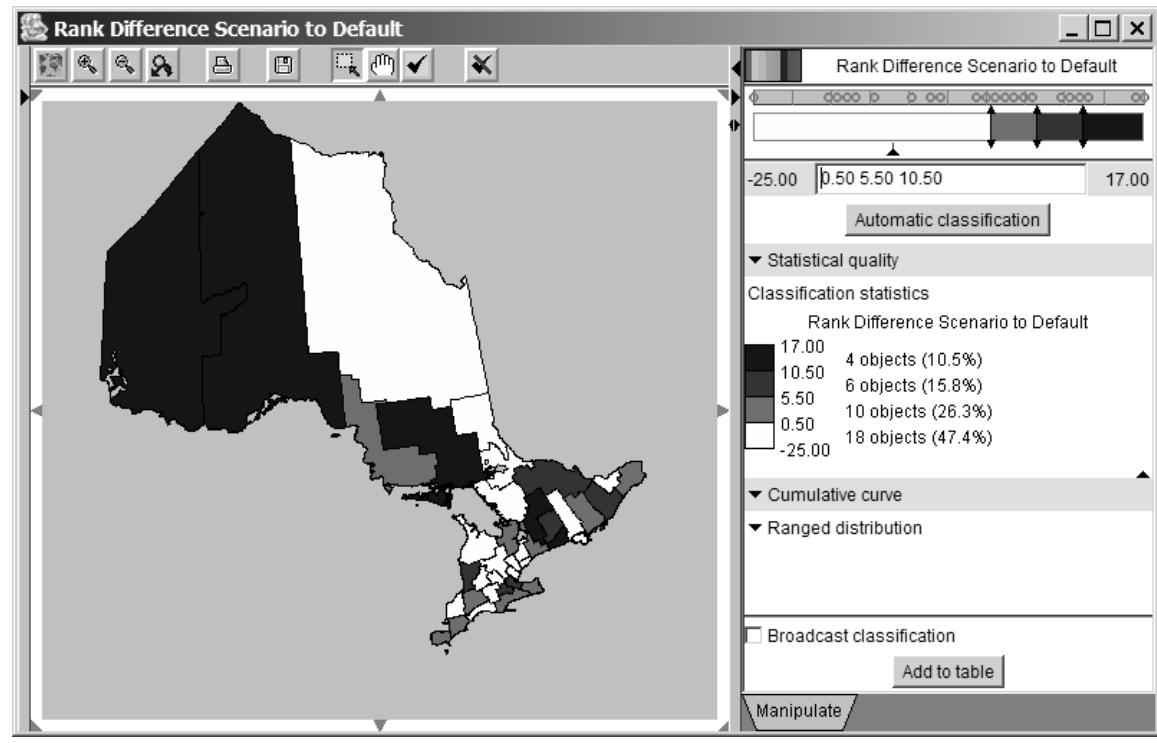

Figure 9 - Change map for the difference in ranks between the hierarchy-derived weighting and a default equal weighting scheme: deterioration of rank is shown in white, improvement in shades of grey with classes for improvement of up to five, up to ten, and more than ten ranks 
At this point the decision analyst may decide to question and review preferences specified earlier in the Analytic Hierarchy Process. If the analyst has additional knowledge or intuition indicating that all three Northern health regions should instead perform similarly, perhaps too much weight was given to Physical Activity? Figure 8 shows a series of rankings created by interactively decreasing the weight of Physical Activity within its group from $60 \%$ to $30 \%$. In Figure 8(a), North-westerly public health units loose ranks with decreasing weight of Physical Activity, while Southern Ontario detailed in Figure 8(b) exhibits stable relative ranks with a slight improvement for some units. Is long-term unemployment really slightly more important than overall unemployment as a health indicator? Why is smoking somewhat more important as an indicator than drinking? At this stage, individual pairwise comparisons may be revised - changes in attribute weighting or hierarchy layout will be applied on-the-fly and their results show up on the evaluation map instantaneously. By opening another instance of an MCE method such as the AHP within the same CommonGIS session, the user can view multiple maps resulting from different weighting schemes. It is also possible to create difference maps ("change maps") using CommonGIS' arithmetic calculation function. Figure 9 shows the difference in ranks between the weights derived in the above scenario and a "default" equal weighting scheme.

\section{Discussion and Conclusion}

This paper describes the use of a multi-criteria evaluation method in a geographical visualization context. In extending previous work on individualized decision strategies in visual spatial decision support, we have shown that the AHP method adds an additional level of user preferences - the criterion hierarchy - to the parameters of a decision rule that can be modified by the decision maker. In using an interactive approach to preference setting, we have demonstrated that criticisms on MCE methods can be effectively addressed by providing an expert user with exploratory tools for geographic visualization and analysis of decision outcomes. This allows for fine-tuning the decision strategy with a view on geographic space. To paraphrase a well-known proverb, an interactive mapping tool is worth a thousand numbers, in that it provides multiple cartographic representations for changing decision-making preferences.

The interactive spatial AHP method has been applied to the assessment of population health status. It handles a large set of attributes, helps the user to simplify the problem, and deals with inconsistencies in the user's preference judgments. The high degree of interactivity, both in giving instant feedback and in accepting changes on-the-fly, helps the decision maker to focus on improving judgments and analyzing the data. However, there are some drawbacks to the approach that should be mentioned. The AHP is not well suited for very small data sets, as it adds overhead to the problem formulation. The scores calculated by the AHP (as with other MCE methods) are useful for finding the relative ranking of the given decision alternatives, but due to necessary standardization, the scores are not meaningful when compared to other sets of alternatives. A shortcoming of this implementation is that ties in ranks derived from evaluation scores are not currently handled in CommonGIS.

Criticism of the AHP method includes the difficulty of interpreting pairwise comparisons and the rank reversal problem (Malczewski 1999). Some of the linguistic labels for comparison levels proposed by Saaty (1980), such as "moderately more important" for three-fold importance, seem non-intuitive in that they suggest smaller differences in importance than the associated numeric factors. However, we do not discuss this issue here as we feel that software tools can easily be adapted if AHP researchers agree on more appropriate labels and factor values.

Malczewski (1999) argues that the decision-maker also needs to know which value ranges of two attributes are compared to each other and that one might think of average values in each attribute. Interactive and dynamically linked maps and graphs as used in the proposed method provide an 
opportunity to explore value ranges and distributions, thus alleviating this criticism. The problem of reversed ranks when new decision alternatives are added during an AHP can be addressed by varying the standardization method (Millet and Saaty 2000). In addition, in the given case study, new alternatives would not normally appear as the set of alternatives covers the entire study area.

Further work on this exploratory spatial AHP implementation is envisioned in two areas. The standardisation of attribute values is currently fixed to score-range transformation but should be offered as an interactive feature like other elements of the decision rule. Exporting weights to other methods is already possible, but still inflexible. Ideally, the user would have both the AHP and another decision support method's dialog open and dynamically linked, so that changes in one could influence the other directly. For example, AHP could be used as a reliable way of determining criterion weights while another method might be preferred for criterion aggregation.

\section{Acknowledgements}

This research was funded by the Natural Sciences and Engineering Research Council of Canada (NSERC) with grants to both authors. Jacek Malczewski provided helpful comments in the course of the project. Valuable comments by three anonymous reviewers are gratefully acknowledged. We would also like to thank the Spatial Decision Support Team at the Fraunhofer Institute for Autonomous Intelligent Systems for granting access to the CommonGIS source code.

\section{References}

Andrienko N and Andrienko G 2003 Informed spatial decisions through coordinated views. Information Visualization 2(4): 270-285

Banai R 1993 Fuzziness in geographic information systems: Contributions from the analytic hierarchy process. International Journal of Geographical Information Systems 7(4): 315-329

Bédard Y, Gosselin P, Rivest S, Proulx M-J, Nadeau M, Lebel G, and Gagnon M-F 2003 Integrating GIS components with knowledge discovery technology for environmental health decision support. International Journal of Medical Informatics 70: 79-94

Birch S, Jerrett M, and Eyles J 2000 Heterogeneity in the determinants of health and illness: the example of socio-economic status and smoking. Social Science and Medicine 51(2): 307-317

Carver S J 1991 Integrating multi-criteria evaluation with geographical information systems. International Journal of Geographical Information Systems 5(3): 321-339

Church R L, Loban S R, and Lombard K 1992 An interface for exploring spatial alternatives for a corridor location problem. Computers and Geosciences 8(10): 1095-1105

CommonGIS 2005 CommonGIS - Thematic mapping for everyone... everywhere. CommonGIS product Web page. Available online at http://www.commongis.com [last visited: 20 January 2005]

Densham P J and Armstrong M P 1995 Human-computer interaction: considerations for visual interactive locational analysis. In Nyerges T L, Mark D M, Laurini R, and Egenhofer M J (eds) Cognitive Aspects of Human-Computer Interaction for Geographical Information Systems. Dordrecht, Kluwer Academic Publishers, pp. 179-196

DiBiase D 1990 Visualization in the earth sciences. Earth and Mineral Sciences, Bulletin of the College of Earth and Mineral Sciences, Penn State University, 59(2) 13-18 
Divisek D and Meyersiek R 2001 Implementation des Analytic Hierarchy Process (AHP) als Java Applet [Implementation of the Analytic Hierarchy Process (AHP) as a Java Applet]. Available online at http://www.meyersiek.de/robin/studium/AHP-Seminar/index.htm [last visited: 29 September 2004]

Eastman J R 1997 IDRISI for Windows, Version 2.0: Tutorial exercises. Graduate School of Geography, Clark University, Worcester, MA

Eastman J R 2003 IDRISI Kilimanjaro - Guide to GIS and Image Processing. Manual Version 14.00. Clark Labs, Clark University, Worcester, MA

Goel V, Iron K, and Williams I 1996 Indicators of Health Determinants and Health Status. In Goel V, Williams J I, Anderson G M, Blackstien-Hirsch P, Fooks C, and Naylor C D (eds) Patterns of Health Care in Ontario. The ICES Practice Atlas, 2nd edition, Ottawa, Canadian Medical Association. Available online at http://www.ices.on.ca/ [last visited: 26 January 2006]

Heywood I, Oliver J, and Tomlinson S 1995 Building an exploratory multi-criteria modelling environment for spatial decision support. In Fisher P (ed) Innovations in GIS 2. London, Taylor and Francis, pp. 127-136

Institute of Population and Public Health (IPPH) 2002 Mapping and Tapping the Wellsprings of Health, Strategic Plan - 2002-2007, Executive Summary. Available online at http://www.cihrirsc.gc.ca/e/12275.html [last visited: 26 January 2006]

Irbarren C, Friedman G D, Klatsky A L, and Eisner M D 2001 Exposure to environmental tobacco smoke: association with personal characteristics and self reported health conditions. Journal of Epidemiology and Community Health 55(10): 721-728

Jankowski P 1995 Integrating geographical information systems and multiple criteria decision making methods. International Journal of Geographical Information Systems 9(3): 251-273

Jankowski P, Andrienko N, and Andrienko G 2001 Map-centered exploratory approach to multiple criteria spatial decision making. International Journal of Geographical Information Science 15(2): 101-127

Janssen R and Rietveld P 1990 Multicriteria analysis and geographical information systems: An application to agricultural land use in the Netherlands. In Scholten H J and Stillwell J C H (eds) Geographical Information Systems for Urban and Regional Planning. Dordrecht, Kluwer Academic Publishers, pp. 129-139

Kosteniuk J G and Dickinson H D 2003 Tracing the social gradient in the health of Canadians: primary and secondary determinants. Social Science and Medicine 57(2): 263-276

MacEachren A M 1994 Visualization in modern cartography: setting the agenda. In: MacEachren A M and Taylor D R F (eds) Visualization in Modern Cartography. Oxford, Pergamon Press, pp. $1-12$

Malczewski J 1999 GIS and Multicriteria Decision Analysis. New York, John Wiley

Millet I and Saaty T L 2000 On the relativity of relative measures \pm accommodating both rank preservation and rank reversals in the AHP. European Journal of Operational Research 121: 205212

Monmonier M 1989 Geographic brushing: enhancing exploratory analysis of the scatterplot matrix. Geographical Analysis 21: 81-84

Natural Resources Canada (NRCan) 2004 The Atlas of Canada, Non-medical Determinants of Health. Available online at 
http://atlas.gc.ca/site/english/maps/health/nonmedicaldeterminantsofhealth [last visited: 26 January 2006]

Pereira J M C and Duckstein L 1993 A multiple criteria decision-making approach to GIS-based land suitability evaluation. International Journal of Geographical Information Systems 7(5): 407424

Rinner C and Malczewski J 2002 Web-enabled spatial decision analysis using Ordered Weighted Averaging (OWA). Journal of Geographical Systems 4(4): 385-403

Rushton G 2003 Public Health, GIS, and Spatial Analytic Tools. Annual Review of Public Health 24: $43-56$

Saaty T L 1980 The Analytic Hierarchy Process. New York, McGraw-Hill

Shneiderman B 2004 The Happy Marriage of Geographic Information Systems and Information Visualization. Keynote lecture at the Third International Conference on Geographic Information Science (GIScience), 20-23 October 2004, College Park, MD

Statistics Canada 2002 How healthy are Canadians? Supplement to Health Reports, vol. 13. Available online at http://www.statcan.ca/english/freepub/82-003-SIE/82-003-SIE2002001.htm [last visited: 26 January 2006]

Statistics Canada 2004 Health Indicators, June 2004. Data tables, Non-medical determinants of health. Available online at http://www.statcan.ca/english/freepub/82-221-XIE/00604/toc.htm [last visited: 20 January 2005]

Voss H, Andrienko N, and Andrienko G 2000 CommonGIS - Common Access to Geographically Referenced Data. Ercim News No 41, April 2000, pp. 44-46. Available online at http://www.ercim.org/publication/Ercim_News/enw41/voss.html [last visited: 20 January 2005]

Wen M, Browning C R, and Cagney K A 2003 Poverty, affluence, and income inequality: neighborhood economic structure and its implications for health. Social Science \& Medicine 57(5): $843-860$

Zhu X and Dale A P 2001 JavaAHP: A Web-based decision analysis tool for natural resource and environmental management. Environmental Modelling \& Software 16(3): 251-262 